\title{
The Metal Effect on Self-Assembling of Oxalamide Gelators Explored by Mass Spectrometry and DFT Calculations
}

\author{
Dario Dabić, ${ }^{1}$ Lidija Brkljačić, ${ }^{2}$ Tana Tandarić, ${ }^{3}$ Mladen Žinić, ${ }^{4}$ Robert Vianello, ${ }^{3}$ \\ Leo Frkanec, ${ }^{4}$ Renata Kobetić ${ }^{5}$
}

${ }^{1}$ Department of Analytical Chemistry, Faculty of Chemical Engineering and Technology, University of Zagreb, Marulićev trg 19, 10000, Zagreb, Croatia

${ }^{2}$ Laboratory for Carbohydrate, Peptide and Glycopeptide Research, Division of Organic Chemistry and Biochemistry, Ruđer Bošković Institute, Bijenička cesta 54, 10000, Zagreb, Croatia

${ }^{3}$ Computational Organic Chemistry and Biochemistry Group, Division of Organic Chemistry and Biochemistry, Ruđer Bošković Institute, Bijenička cesta 54, 10000, Zagreb, Croatia

${ }^{4}$ Laboratory of Supramolecular Chemistry, Division of Organic Chemistry and Biochemistry, Ruđer Bošković Institute, Bijenička cesta 54, 10000, Zagreb, Croatia

${ }^{5}$ Laboratory for Biomolecular Interactions and Spectroscopy, Division of Organic Chemistry and Biochemistry, Ruđer Bošković Institute, Bijenička cesta 54, 10000, Zagreb, Croatia

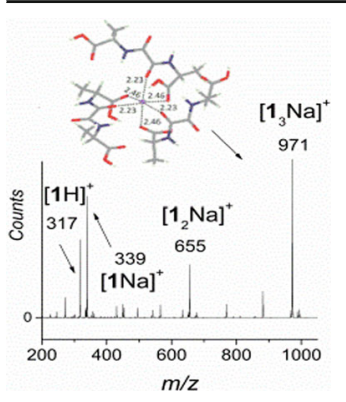

carboxyl groups. The variation of solvents from polar aprotic towards polar protic did not have any significant effects on the size of the assemblies. The addition of a salt such as $\mathrm{NaOAc}$ or $\mathrm{Mg}(\mathrm{OAc})_{2}$, depending on the concentration, altered the assembling. Computational analysis at the DFT level aided in the interpretation of the observed trends and revealed that individual gelator molecules spontaneously assemble to higher aggregates, but the presence of the $\mathrm{Na}^{+}$cation disrupts any gelator organization since it becomes significantly more favorable for gelator molecules to bind $\mathrm{Na}^{+}$cations up to the $3: 1$ ratio than to self-assemble, being fully in line with experimental observations reported here.

Keywords: Oxalamide gelators, Self-assembly, ESI-MS, DFT

Abstract. Gels formed by self-assembly of small organic molecules are of wide interest as dynamic soft materials with numerous possible applications, especially in terms of nanotechnology for functional and responsive biomaterials, biosensors, and nanowires. Four bis-oxalamides were chosen to show if electrospray ionization mass spectrometry (ESI-MS) could be used as a prediction of a good gelator and also to shed light on the gelation processes. By inspecting the gelation of several solvent, we showed that bis(amino acid)oxalamide 1 proved to be the most efficient, also being able of forming the largest observable assemblies in the gas phase. The formation of singly charged assemblies holding from one up to six monomer units is the outcome of the strong intermolecular $\mathrm{H}$-bonds, particularly among terminal Received: 16 May 2017/Revised: 2 October 2017/Accepted: 10 October 2017/Published Online: 30 October 2017

\section{Introduction}

$I^{n}$ ndividual molecules can self-assemble into oligomers as a consequence of molecular recognition interactions between

\footnotetext{
Electronic supplementary material The online version of this article (https:// doi.org/10.1007/s13361-017-1834-5) contains supplementary material, which is available to authorized users.
}

Correspondence to: Robert Vianello; e-mail: Robert.Vianello@irb.hr, Leo Frkanec; e-mail: Leo.Frkanec@irb.hr, Renata Kobetić; e-mail: rkobetic@irb.hr the building blocks [1]. These oligomers subsequently grow to form fibrils by the same process and, in many cases, the fibrils then bundle together to form fibers. These fibers subsequently form extended networks, which are capable of supporting the gel [2].

To comprehend gelation induced by small organic molecules, it is of utmost importance to reveal the relationship between the gelator structure, gelled solvent properties, and the organization in fibrous supramolecular aggregates constituting the three-dimensional gel network [3]. Precise knowledge of this relationship would allow a reliable and target 
design of a specific gelator for a liquid with selected properties as well as the preparation of gels suitable for various applications, especially in terms of nanotechnology for functional and responsive biomaterials, biosensors, and nanowires [4].

Oxalamides, being simple mono-substituted diamides of oxalic acid, represent construction units with a high in-plane hydrogen bonding potential; they are self-complementary, capable of unidirectional hydrogen bonding and, hence, ideally suited for the construction of self-assembled supramolecular systems of fibrous morphology. Our group has long-term experience in design, synthesis, and characterization of low molecular weight gelators, especially bis(amino acid)oxalamides [5-9]. They exhibit ambidextrous gelation properties, being capable of forming gels with apolar and also highly polar solvent systems and tend to organize either into bilayers or inverse bilayers in hydrogel or organic solvent gel assemblies, respectively. It is worth noting that the bulk solvent is immobilized as a consequence of capillary forces, with individual solvent molecules actually retaining their mobility within the gel on the molecular scale. ${ }^{1} \mathrm{H}$ NMR and FTIR studies of gels revealed the importance of the equilibrium between the assembled network and smaller dissolved gelator assemblies [10]. The organization in gel assemblies deduced from spectroscopic structural studies are in certain cases closely related to the organizations found in the crystal structures of selected gelators, confirming similar organizations in gel assemblies and in the solid state. Mixing of the constitutionally different bis(amino acid) and bis(amino alcohol)oxalamide gelators resulted, in some cases, in highly improved gelation efficiency denoted as synergic gelation effect (SGE) [11], being also highly dependent on the stereochemistry of the component gelators. Applications of oxalamide units in crystal- and bioengineering may open new perspectives in the utilization of these systems as powerful and versatile organizational and directional element for the future construction of novel abiotic and biotic supramolecular systems.

The commonly used methods for the characterization of supramolecular gels are nuclear magnetic resonance spectroscopy, computational molecular simulations, X-ray and microscopy techniques, dynamic light scattering, thermal analysis, and rheology [12]. In addition to the commonly used methods mentioned above, other methods such as mass spectrometry have been sometimes used for the characterization of supramolecular gels. Thus, MacLachlan and coworkers used electrospray ionization mass spectrometry (ESI-MS) to get a snapshot of large aggregates of zinc salophen complexes in solution, which provided evidence for the formation of metal- containing gel [13]. Matrix-assisted laser desorption/ionization time-of-flight mass spectrometry (MALDI-TOF-MS) is another especially useful method for the detection of organometallic gelators $[14,15]$.

Electrospray ionization [16, 17], which is a soft ionization technique, has emerged in the past decade as an indispensable tool for analyzing supramolecular assemblies that contain noncovalent bonds [18-21]. The advantage of ESI is that it keeps the internal energy of the ions low and thus not only suppresses extensive fragmentation but also makes the intact ionization of non-covalent assembles feasible. Moreover, the analyte can be ionized from almost any suitable solution, provided that a charge is present in the complex or can be delivered to it during ionization. A factor that governs whether tandem MS of noncovalent complexes can yield any structural information is the relative stability of the gas phase complex, which promotes intrinsic organization of the individual gelator molecules not influenced by the presence of any solvent or counterions.

The motivation for this work was to explore the difference in the gas phase self-organization as an indicator of molecular recognition interactions between the oxalamide building blocks. The physical linking could be observed due to the non-covalent supramolecular interactions. Beside, an organogelation process depends on the gelator-solvent pair. It is well established that this choice has a major importance in the search for specific properties of the material. Even though a lot of attention has been paid to the gelators, the solvent is usually chosen by a trial-error approach. Prediction of gelation potential of a given molecule might seem possible by investigation of its propensity towards chemical or physical intermolecular interactions; however, no generalizations are so far possible. In this paper, we highlight that the preserved selforganization observed in the gas phase via ESI-MS could possibly be an indication of good gelation properties. Namely, the self-assembling of compounds 1-4 (Figure 1) dissolved in protic and aprotic polar solvents and in the mixtures with non polar but very good gelling solvents was examined and the most interesting results are presented. The disruption of the gels with sodium and magnesium ions was examined experimentally and corroborated computationally.

\section{Experimental}

\section{General}

The solvents used for the spectroscopic measurements were HPLC or spectroscopic grade (Sigma-Aldrich Chemie GmbH,

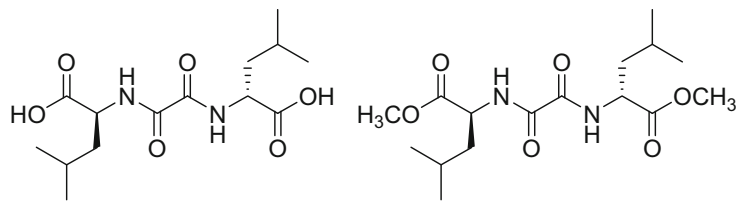

1

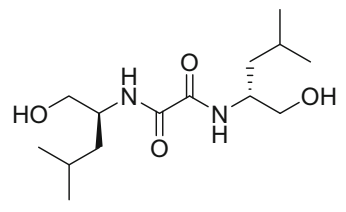

3

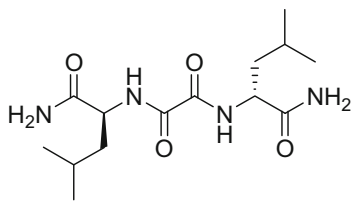

4

Figure 1. Structure of studied bis(amino acid/ester/alcohol)oxalamide gelators 1-4 
Steinheim, Germany) and were used without further purification. Salts $\mathrm{Mg}(\mathrm{OAc})_{2}$ and $\mathrm{NaOAc}$ were purchased (SigmaAldrich Chemie GmbH, Steinheim, Germany; Merck AG, Darmstadt, Germany) and were used without further purification.

\section{Synthesis}

Compounds 1-4 (Figure 1) were prepared in our laboratory according to previously described methods $[5,7,22]$.

\section{Instrumentation}

Self-assembling of compounds 1-4 (Figure 1) was studied by ESI, using the ion trap for $\mathrm{MS}^{\mathrm{n}}$ studies, and triple-quadrupole for ESI-MS/MS studies. The spectra were obtained at the same concentrations and conditions in both positive ion $\left(\mathrm{ES}^{+}\right)$and negative ion $\left(\mathrm{ES}^{-}\right)$modes. Certain fragmentations occurred at higher collision energies. The fragmentation pathways for all analyzed compounds were proposed based on MS/MS and $\mathrm{MS}^{\mathrm{n}}$ spectra of protonated molecular ions $[\mathrm{M}+\mathrm{H}]^{+}$or deprotonated molecular ions $[\mathrm{M}-\mathrm{H}]^{-}$as well as sodium adducts.

1. The mass spectral data were acquired using an Agilent 6420 Triple Quad mass spectrometer equipped with an electrospray ionization interface operated in the $\mathrm{ES}^{+}$and $\mathrm{ES}^{-}$modes (Agilent Technologies, Palo Alto, CA, USA). The samples were prepared in water, $\mathrm{D}_{2} \mathrm{O}$, methanol, methanol- $\mathrm{d}_{4}$, ethanol, ethanol- $\mathrm{d}_{6}$, acetonitrile, acetonitrile- $\mathrm{d}_{3}$ with and without $\mathrm{NaOAc}$, or $\mathrm{Mg}(\mathrm{OAc})_{2}$ to a concentration of about $0.05 \mathrm{mg} / \mathrm{mL}$ and directly injected. The infusion into the mass spectrometer was performed at a flow rate of $3 \mu \mathrm{L} /$ min. Nitrogen was used as an auxiliary and sheath gas. The spray voltage was set at $4.5 \mathrm{kV}$. The capillary temperature was $150-300{ }^{\circ} \mathrm{C}$, and the voltage range of the collision cell was $80-180 \mathrm{~V}$. The full mass spectra were acquired over the mass range $m / z 10-2000$. For data acquisition and analysis, Mass Hunter software (Agilent Technologies, Inc. 2006007) was used. A parent ion window of typically 4 u (i.e., parent mass $\pm 2 \mathrm{u}$ ) was chosen to perform further MS/MS experiments.

2. The ESI-MS ${ }^{n}(n>2$, a parent ion window of typically $2 u$ (i.e., parent mass $\pm 1 \mathrm{amu})$ ) experiments were recorded using an amaZon ETD mass spectrometer (Bruker Daltonik, Bremen, Germany) equipped with the standard ESI ion source (the nebulizer pressure: $8 \mathrm{psi}$; the drying gas flow rate: $5 \mathrm{~L} / \mathrm{min}$; the drying gas temperature: $250^{\circ} \mathrm{C}$ ). The mass spectrometer was operated in the positive and negative polarity modes, and the potential on the capillary cap was $-/+4500 \mathrm{~V}$. Helium was used as a collision gas. The samples were prepared in water, $\mathrm{D}_{2} \mathrm{O}$, methanol, methanol- $\mathrm{d}_{4}$, ethanol, ethanol- $\mathrm{d}_{6}$, acetonitrile, acetonitrile- $\mathrm{d}_{3}$ with and without $\mathrm{NaOAc}$ or $\mathrm{Mg}(\mathrm{OAc})_{2}$ to a concentration of about $0.5 \times 10^{-6} \mathrm{~mol} / \mathrm{dm}^{3}$ and injected into the ESI source of the mass spectrometer by a syringe pump at a flow rate of $1 \mu \mathrm{L} / \mathrm{min}$.

\section{Computational Details}

As a good compromise between accuracy and the computational feasibility, all geometries were optimized by the very efficient M06-2X/6-31+G(d) method in the gas phase with thermal Gibbs free energy corrections extracted from the corresponding frequency calculations without the scaling factors. The final single-point energies were attained with a highly flexible 6-311++G(d,p) basis set giving rise to the M06-2X/6$311++\mathrm{G}(\mathrm{d}, \mathrm{p}) / / \mathrm{M} 06-2 \mathrm{X} / 6-31+\mathrm{G}(\mathrm{d})$ model used here. In this way all of the reported computational data correspond to the gas-phase Gibbs free energies at a temperature of $298.15 \mathrm{~K}$ and a pressure of $1 \mathrm{~atm}$. The choice of such a computational setup was prompted by our recent success in modeling the properties of gelator molecules [23] and metal binding affinities [24], as well as correctly reproducing thermodynamic and kinetic parameters of organic $[25,26]$ and enzymatic [27] reactions. In order to circumvent problems with the flexibility of the investigated systems, we tried many different conformations in each studied case and report here the results corresponding to the most stable structures. All calculations were performed by using the Gaussian 09 program package [28].

\section{Results and Discussion}

A brief overview of the MS profile of the model compounds 1-4 is presented first, followed by the elucidation of the new species formed attributable to their non-covalent interactions. A detailed study was performed in the gas phase using CID (collision induced dissociation) experiments (ESI-MS/MS) and by the gas-phase density functional theory (DFT) calculations.

Bis(amino acid)oxalamide gelators or bis(amino alcohol)oxalamide are constructed from oxalo retro bipeptides. The core oxalyl (-CO-CO-) unit in this molecule can be considered as a dimerization element that links two identical amino acids into a novel $\mathrm{C} 2$ symetric retro-bispeptide wherein the oxalamido (-NH-CO-CO-NH-)unit is locked in a perfect trans conformation [29]. The pseudo $\mathrm{C}_{5}$ type intramolecular hydrogen bonding motif is responsible for the formation of highly organized self-assemblies [30, 31].

Bis(amino acid)-, 1, bis(amino ester)-, 2, bis(amino amide)-, 3, and bis(amino alcohol)-, 4, oxalamide gelators represent a class of versatile gelators, the gelation ability of which is a consequence of both strong and directional intermolecular hydrogen bonding provided by oxalamide units, and a lack of molecular symmetry attributable to the presence of two chiral centers. Even though ESI is a mild technique and the noncovalent interactions such as hydrogen bonding or electrostatic interactions could be transferred into the gas phase of the instrument, we did not neglect the fact that during the transition from condensed phase into high vacuum, various properties of the non-covalent bonds - strength, directionality, and geometry - may significantly change. Any interaction that competes with the solvent could, upon evaporation, either increase in strength (like hydrogen bonds or electrostatic interactions) or decrease in strength (like hydrophobic interactions). Taking all of this 
into account, we believe that the observed results in the gas phase could be related to the gelation tendency of four compounds presently studied.

\section{Terminal Group Effect on Self-Organization in Gas Phase}

The first part of the study is focused on the comparison of the terminal groups of four oxalamides: $\mathrm{COOH}, \mathrm{CH}_{2} \mathrm{OH}$, $\mathrm{COOCH}_{3}$, and $\mathrm{CONH}_{2}$, and their influence towards self-assembling. Bis(amino acid)oxalamide 1 proved to be the best of all four studied gelators by gelling all studied solvents, (Supplementary Information Table S1). Transfer to gas phase and the detection of created self-assemblies of $\mathbf{1}$ was examined in different solvents via ESI-MS. Several intensive signals were observed in full scan spectra of $\mathbf{1}$ assigned as hydrogen or sodium adducts or various sizes of self-assembled units together, Figure 2 . The formation of singly charged assemblies holding from one up to six (possibly even more) monomer units was the outcome of the strong intermolecular H-bonds, Table 1 . The hypothesis was to check if the variation of the

a)

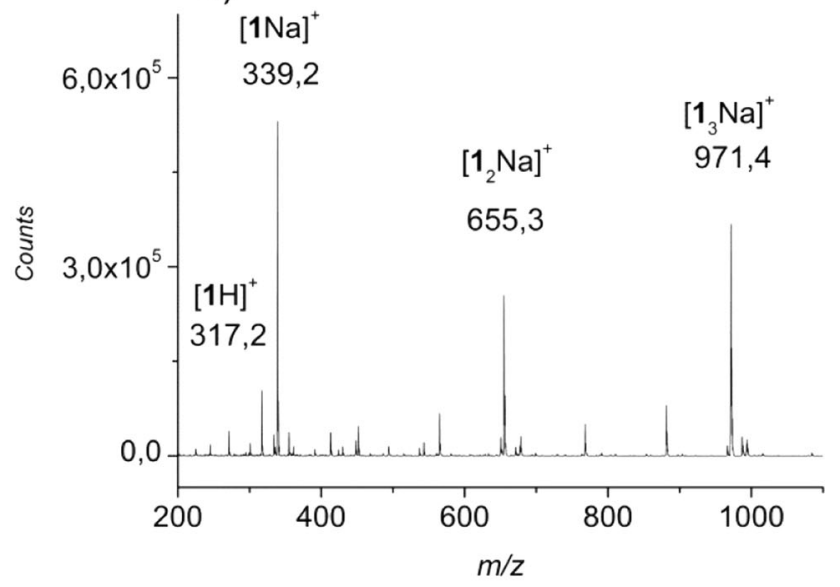

b)

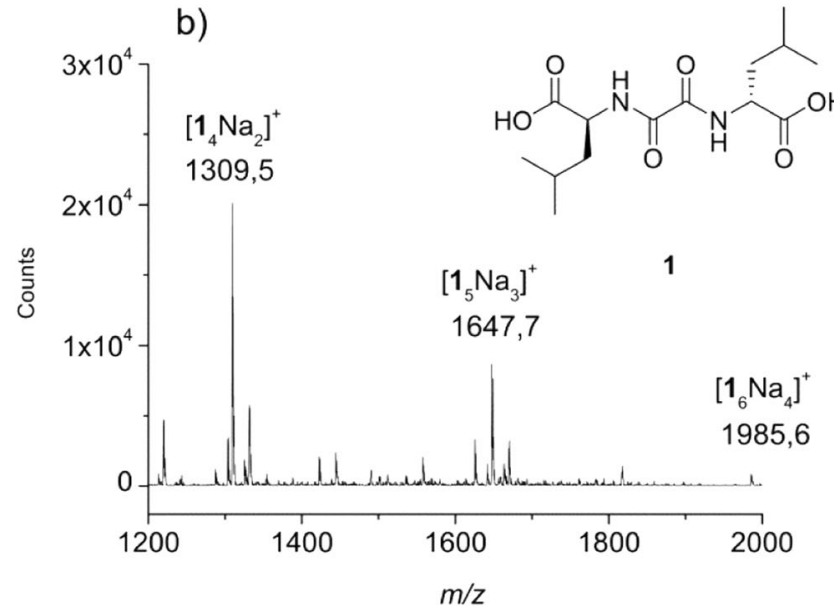

Figure 2. Full scan $\mathrm{ES}^{+}$spectrum for bis(amino acid)oxalamide 1 dissolved in water about $10^{-5} \mathrm{M}$; divided to two $\mathrm{m} / \mathrm{z}$ regions (a) 200-1000; (b) 1200-2000 for clarity specific solvation driven by protic capabilities of the solvent could obstruct the formation of hydrogen bonds between the gelator building blocks. The variation of the solvent: acetonitrile (polar aprotic) towards methanol, ethanol, or water (polar protic) did not have any significant effects on the size of the observable assemblies, pointing out that intermolecular hydrogen bonding overcome specific solvation effects as well as other non-covalent interactions. This observation confirms the fact that the bulk solvent is immobilized as a consequence of capillary forces, with individual solvent molecules actually retaining their mobility within the gel on the molecular scale. It also agrees with their ambidextrous gelation properties: being capable of forming gels with apolar and also highly polar solvent systems and tending to organize either into bilayers or inverse bilayers in hydrogel or organic solvent gel assemblies, respectively.

The analysis of the collision induced fragmentation spectra of major observed signals pointed out that the decaboxylation of $\mathrm{H}$-adduct assemblies occurred very easily in both modes $\left(\mathrm{ES}^{+/}\right)$showing the strength of the intermolecular H-bonds. It was confirmed by the presence of the fragments at $\mathrm{m} / \mathrm{z} 271$ or 226 in $\mathrm{ES}^{+}$assigned as the mono- and didecaboxylated monomer of acid 1 (Supplementary Information Figures S2 and S3) or $\mathrm{m} / \mathrm{z} 541$ and 585 in $\mathrm{ES}^{-}$assigned as the mono- and didecaboxylated dimer of acid 1. Sodium adducts had higher prevalence (values shown in italic in Table 1) and did not show any decarboxylation products; alternatively, the departure of the monomer units was observed, which was the dominating fragmentation path in all sodium adducts studied. There was also the difference in stability of the observed adducts. Namely, the fragmentation of the protonated species such as one at $\mathrm{m} / \mathrm{z}$ 428 decarboxylated already at $\mathrm{CE} 5 \mathrm{eV}$, whereas the sodium adducts did not decarboxylate easily $(\mathrm{CE} \geq 15 \mathrm{eV})$.

Three other low molecular weight gelators (LMWG) $(\mathbf{2}, \mathbf{3}$, and 4) were examined in order to compare their assembling regarding their structural differences: the variation was in terminal groups: $\mathrm{COOCH}_{3}, \mathrm{CONH}_{2}$, and $\mathrm{CH}_{2} \mathrm{OH}$. The evaluation of the self organization of compounds demonstrated that bis(amino ester) oxalamide, 2, and bis(amino alcohol) oxalamide, 3, formed dimers as the largest species, Figure 3, whereas bis(amino acid) oxalamide, $\mathbf{1}$ and bis(aminoamide) oxalamide, $\mathbf{4}$ self organized in larger aggregates (six and more monomers in aggregates), Figure 4 and Table 1.

Alcohol $\mathbf{3}$ and ester $\mathbf{2}$ have oxalamide hydrogens capable of forming intermolecular H-bonds analog to acid $\mathbf{1}$ or amide $\mathbf{4}$ but it seems that the additional hydrogen from either the terminal carboxyl group or amide group was essential for the formation of a whole new array of aggregates observable in the gas phase in regard to $-\mathrm{OH}$ or $-\mathrm{OCH}_{3}$ groups, Figure 5, as will be confirmed by the computational analysis presented later. The observation of large self-assemblies in the gas phase goes well with the fact that the additional $\mathrm{H}$-bonds were essential for the in source fragmentation survival. Those bonds were responsible obviously for their excellent gelling capabilities too (Supplementary Information Table S1). Additionally, the X-ray data about the self-assembly in the solid phase showed that acid 
Table 1. Species Observed for Self Organized Bis(amino acid) Oxalamide, 1 Dissolved in Acetonitrile (Supplementary info Figure S1a-f for the Spectra in Methanol, Ethanol, Water, Water/NaOAc), and Bis(Amino Amid)oxalamide, 4 in Water, Scanned in $\mathrm{ES}^{+}$Mode

\begin{tabular}{|c|c|c|c|c|c|c|c|c|c|c|c|}
\hline \multicolumn{2}{|l|}{ Monomer } & \multicolumn{2}{|l|}{ Dimer } & \multicolumn{2}{|l|}{ Trimer } & \multicolumn{2}{|l|}{ Tetramer } & \multicolumn{2}{|l|}{ Pentamer } & \multicolumn{2}{|l|}{ Heksamer } \\
\hline Species & $m / z$ & Species & $m / z$ & Species & $\mathrm{m} / \mathrm{z}$ & Species & $m / z$ & Species & $m / z$ & Species & $m / z$ \\
\hline$[1 \mathrm{H}]^{+}$ & 317 & {$\left[1_{2} \mathrm{H}\right]^{+}$} & 633 & {$\left[1_{3} \mathrm{H}\right]^{+}$} & 949 & {$\left[{ }_{1} \mathrm{H}\right]^{+}$} & 1264 & {$\left[1_{5} \mathrm{H}\right]^{+}$} & - & {$\left[1_{6} \mathrm{H}\right]^{+}$} & 1896 \\
\hline$[1 \mathrm{Na}]^{+}$ & 339 & {$\left[\mathrm{I}_{2} \mathrm{Na}\right]^{+}$} & 655 & {$\left[1_{3} \mathrm{Na}\right]^{+}$} & 971 & {$\left[1{ }_{4} \mathrm{Na}\right]^{+}$} & 1287 & {$\left[1{ }_{5} \mathrm{Na}\right]^{+}$} & 1602 & {$\left[1{ }_{6} \mathrm{Na}\right]^{+}$} & 1919 \\
\hline$\left[1 \mathrm{Na}_{2}\right]^{+}$ & 361 & {$\left[1_{2}\left(\mathrm{H}_{2} \mathrm{O}\right)\right]^{+}$} & 651 & {$\left[1_{3}\left(\mathrm{H}_{2} \mathrm{O}\right)\right]^{+}$} & 966 & {$\left[\mathrm{l}_{4} \mathrm{Na}_{2}\right]^{+}$} & 1309 & {$\left[1_{5} \mathrm{Na}_{2}\right]^{+}$} & 1625 & {$\left[1_{6} \mathrm{Na}_{2}\right]^{+}$} & 1941 \\
\hline & & {$\left[1_{2}\left(\mathrm{H}_{2} \mathrm{O}\right)_{2}\right]^{+}$} & 669 & {$\left[1_{3}\left(\mathrm{H}_{2} \mathrm{O}\right)_{2}\right]^{+}$} & 984 & {$\left[1_{4} \mathrm{Na}_{3}\right]^{+}$} & 1331 & {$\left[1_{5} \mathrm{Na}_{3}\right]^{+}$} & 1647 & {$\left[1_{6} \mathrm{Na}_{3}\right]^{+}$} & 1963 \\
\hline & & {$\left[1_{2} \mathrm{Na}_{2}\right]^{+}$} & 677 & {$\left[1_{3} \mathrm{Na}_{2}\right]^{+}$} & 995 & {$\left[1_{4} \mathrm{Na}_{4}\right]^{+}$} & 1353 & {$\left[1_{5} \mathrm{Na}_{4}\right]^{+}$} & 1670 & {$\left[1_{6} \mathrm{Na}_{4}\right]^{+}$} & 1986 \\
\hline & & {$\left[1_{2} \mathrm{Na}_{3}\right]^{+}$} & 699 & {$\left[1_{3} \mathrm{Na}_{3}\right]^{+}$} & 1015 & {$\left[1{ }_{4} \mathrm{~K}\right]^{+}$} & 1303 & {$\left[1_{5} \mathrm{Na}_{5}\right]^{+}$} & 1693 & & \\
\hline & & {$\left[1_{2} \mathrm{~K}\right]^{+-}$} & 671 & {$\left[1_{3} \mathrm{~K}\right]^{+}$} & 987 & {$\left[1_{4} \mathrm{~K}_{2}\right]^{+}$} & 1342 & {$\left[1_{5} \mathrm{Na}_{6}\right]^{+}$} & 1715 & & \\
\hline$[4 \mathrm{H}]^{+}$ & 315 & {$\left[{ }_{2} \mathrm{H}\right]^{+}$} & 629 & {$\left[4{ }_{3} \mathrm{H}\right]^{+}$} & 943 & {$\left[4{ }_{4} \mathrm{H}\right]^{+}$} & 1257 & {$\left[4_{5} \mathrm{H}\right]^{+}$} & 1571 & {$\left[4_{6} \mathrm{H}\right]^{+}$} & 1885 \\
\hline$[4 \mathrm{Na}]^{+}$ & 337 & {$\left[4_{2} \mathrm{Na}\right]^{+}$} & 651 & {$\left[4{ }_{3} \mathrm{Na}\right]^{+}$} & 965 & {$\left[4{ }_{4} \mathrm{Na}\right]^{+}$} & 1279 & {$\left[4{ }_{5} \mathrm{Na}\right]^{+}$} & 1593 & {$\left[4{ }_{6} \mathrm{Na}\right]^{+}$} & 1907 \\
\hline$\left[4 \mathrm{Na}\left(\mathrm{H}_{3} \mathrm{O}\right)\right]^{2+}$ & - & {$\left[4_{2} \mathrm{Na}\left(\mathrm{H}_{3} \mathrm{O}\right)\right]^{2+}$} & 334 & {$\left[4_{3} \mathrm{Na}\left(\mathrm{H}_{3} \mathrm{O}\right)\right]^{2+}$} & 491 & {$\left[4_{4} \mathrm{Na}\left(\mathrm{H}_{3} \mathrm{O}\right)\right]^{2+}$} & 648 & {$\left[4_{5} \mathrm{Na}\left(\mathrm{H}_{3} \mathrm{O}\right)\right]^{2+}$} & 805 & {$\left[4_{5} \mathrm{Na}\left(\mathrm{H}_{3} \mathrm{O}\right)\right]^{2+}$} & 962 \\
\hline
\end{tabular}

formed the $\beta$-network of bis(2-aminopropionic acid)oxalamide structure, whereas ester or alcohol did not [32]. Another interesting observation was a higher abundance for the tetramer and pentamer, the doubly charged assemblies of $\mathbf{4}$ most likely due to better ionization potential of the amide versus acid.

\section{H/D Exchange}

$H / D$ exchange experiments in solutions were performed in order to further confirm the observations regarding the type of the non-covalent interactions between the units in the gas phase. Hydrogen exchange results confirmed that the building blocks are connected via intermolecular hydrogen bonds.

Bis(amino acid)oxalamide $\mathbf{1}$ was dissolved in deuterated solvents. Exchangeable protons in monomer or in the assemblies formed due to the electrostatic interactions were completely replaced. On the other hand, self-assembled dimers, trimers, etc. connected via intermolecular hydrogen bonds exchanged amide protons slower confirming that it was costly and required more energy and time (Supplementary Information Figure S5), since several bonds had to be broken and formed: the intramolecular H-bond, $\mathrm{N}-\mathrm{H}-\mathrm{O}$, and $\mathrm{O}-\mathrm{D}$ from solvent. This is further corroborated by the computational analysis, which, at the M06-2X/6-31+G(d) level of theory, revealed that the free energy required to deprotonate the amide $\mathrm{N}-\mathrm{H}$ group in $\mathbf{1}$ is $5.5 \mathrm{kcal} \mathrm{mol}^{-1}$ higher than to deprotonate the carboxyl COOH group in the monomer, whereas it is $10.5 \mathrm{kcal}$ $\mathrm{mol}^{-1}$ higher in the corresponding dimers. This makes it reasonable to expect that this trend will be maintained even in the higher aggregates, thereby supporting experimental findings. We also observed that the addition of $\mathrm{Mg}^{2+}$ salt altered the $\mathrm{H} / \mathrm{D}$ exchange of the shielded hydrogen more than $\mathrm{Na}^{+}$, Figure 6 .

\section{Disruption of Gels}

The ability of oxalamide derivatives (1-4) to form supramolecular gels by means of extended hydrogen bonded chains has given rise to a rich field of synthetically and externally tunable soft materials, which has been the subject of intense investigation in recent years [5-9, 23]. Addition of hydrochloric acid, various metal salts, or ions to the gels significantly affects their gelation properties. Recently, Steed reported several examples affecting and tuning mechanical properties of urea supramolecular gels by metal addition, the properties of which can be

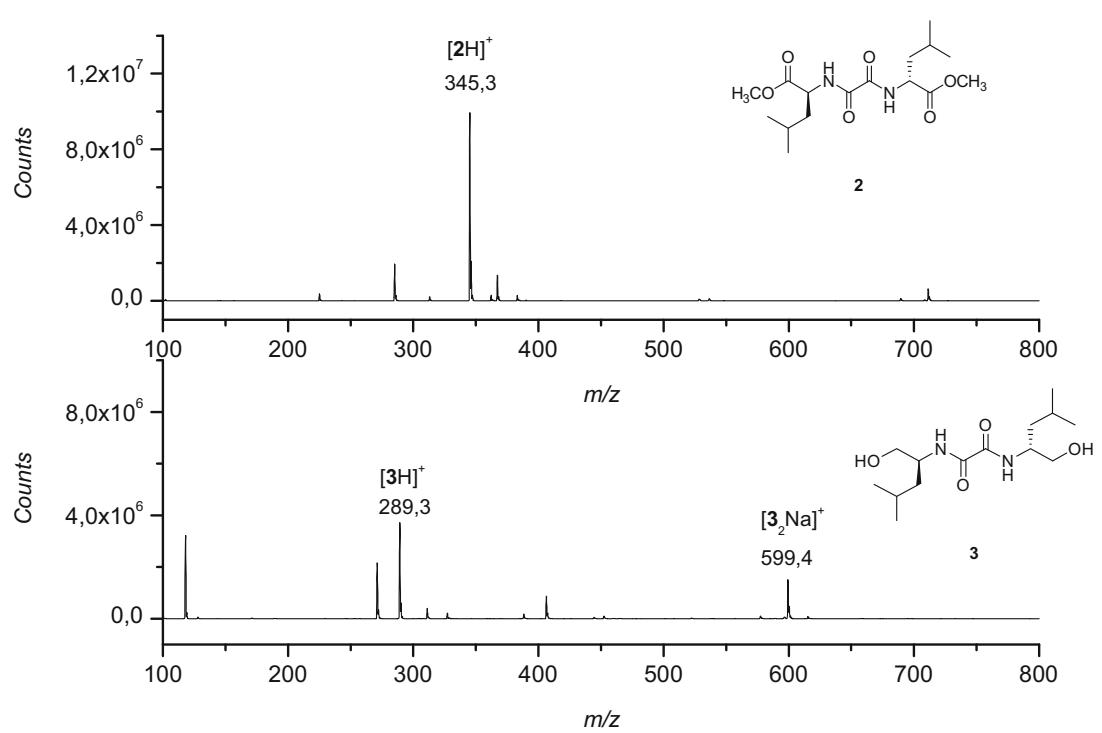

Figure 3. Full scan $\mathrm{ES}^{+}$mass spectra for 2 and $\mathbf{3}$ dissolved in water, in concentration of about $10^{-5} \mathrm{M}$ 


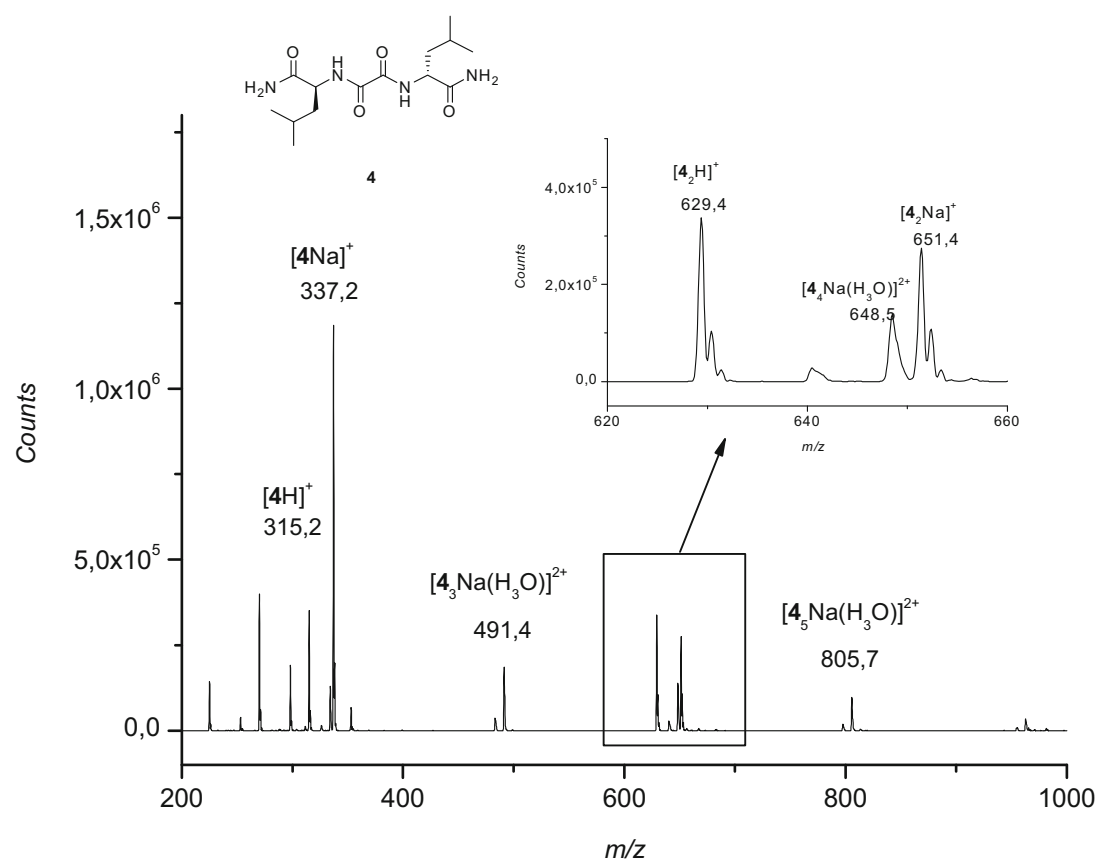

Figure 4. Full scan $\mathrm{ES}^{+}$mass spectrum for 4 dissolved in water, in concentration of about $10^{-5} \mathrm{M}$. Insert shows the signals of the doubly charged species

changed by the coordination metal ion (anion-tuning) or halogen bonding to trigger supramolecular gel formation [33-35].

The addition of salts such as $\mathrm{NaOAc}$ or $\mathrm{Mg}(\mathrm{OAc})_{2}$, depending on the concentration, altered the assembling. Together with the singly charged species, at low concentration of $\mathrm{Mg}^{2+}$ or $\mathrm{Na}^{+}$ doubly charged larger assemblies were observed (Supplementary Information Figure S4). When bis(amino acid)oxalamide 1 was dissolved in aqueous solutions with higher concentrations

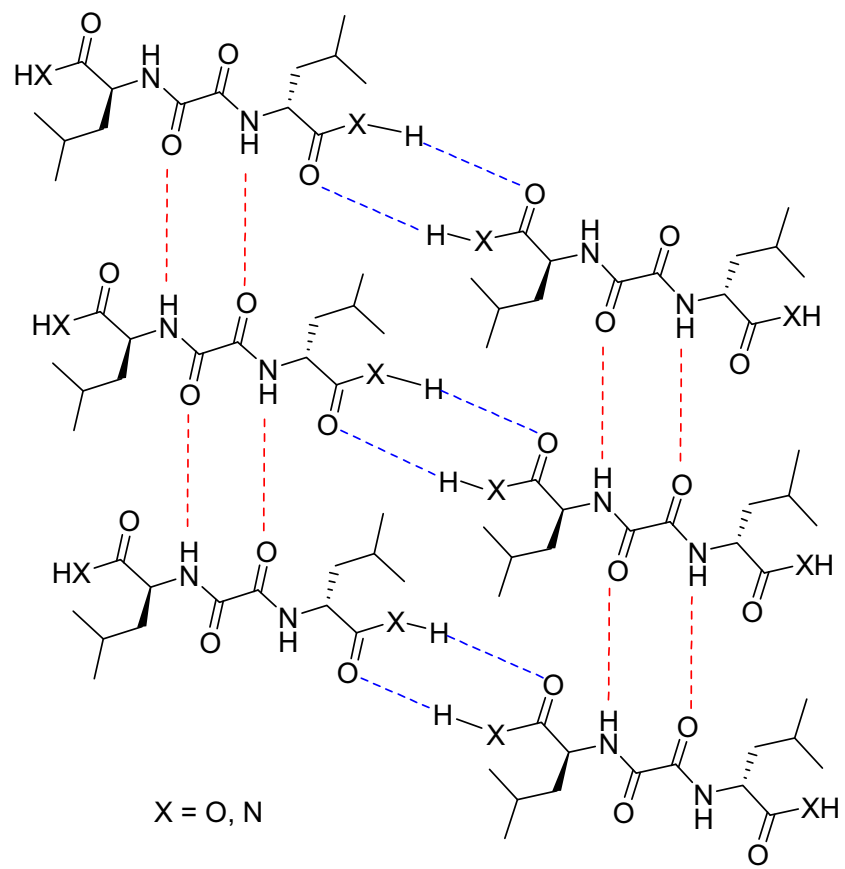

Figure 5. Cartoon showing intramolecular $\mathrm{H}$-bonds vital for the networking and assembling of gelators studied here of $\mathrm{NaOAc}$ or $\mathrm{Mg}(\mathrm{OAc})_{2}$ salts, the formation of larger assemblies failed, being in agreement with the observation in condensed phase that the salt disrupts the gel formation (Supplementary Information Figure S5). This feature will be rationalized by the computational analysis presented later.

The formation of the salt bridges (a combination of two noncovalent interactions: hydrogen bonding and electrostatic interactions) is possible under favorable circumstances. It seems that the salt bridges form between the carboxylic anions and sodium ions in larger assemblies preventing the low energy decarboxylation observed in non-sodium adducts. We know that the addition of sodium ions prevents the gel formation and the already formed gels get destroyed simply by shaking from the solution experiments, as revealed here through the computational analysis. The capability for binding of three sodium ions per monomer unit of $\mathbf{1}$ was observed (Supplementary Information Figure S6 a and b). Our calculations show that the most stable of such structures involves trans gelator molecule with two $\mathrm{Na}^{+}$cations serving as counterions for the carboxyl group at $\mathrm{Na}-\mathrm{O}$ distances between 2.18-2.29 $\AA$, whereas the third $\mathrm{Na}^{+}$ion is bound to one of the carbonyl atoms at 2.24 $\AA$. In the cis analog, two $\mathrm{Na}^{+}$cations are located in the same way in the vicinity of the carboxyl groups, whereas the third $\mathrm{Na}^{+}$ion binds both carbonyl oxygens on the other side of the molecule at the $\mathrm{Na}-\mathrm{O}$ distance of $2.20 \AA$. Still, this is not enough to make the cis analog a dominant conformation, which is $1.8 \mathrm{kcal} \mathrm{mol}^{-1}$ less stable than the trans counterpart.

There were no larger than four units assembled together at higher concentrations of sodium ions, suggesting that the electrostatic interaction dominated over the hydrogen bonding, e.g., the affinity of $\mathrm{C}=\mathrm{O}$ toward sodium ion was greater than towards hydrogen of the other gelator molecule. Binding of the 

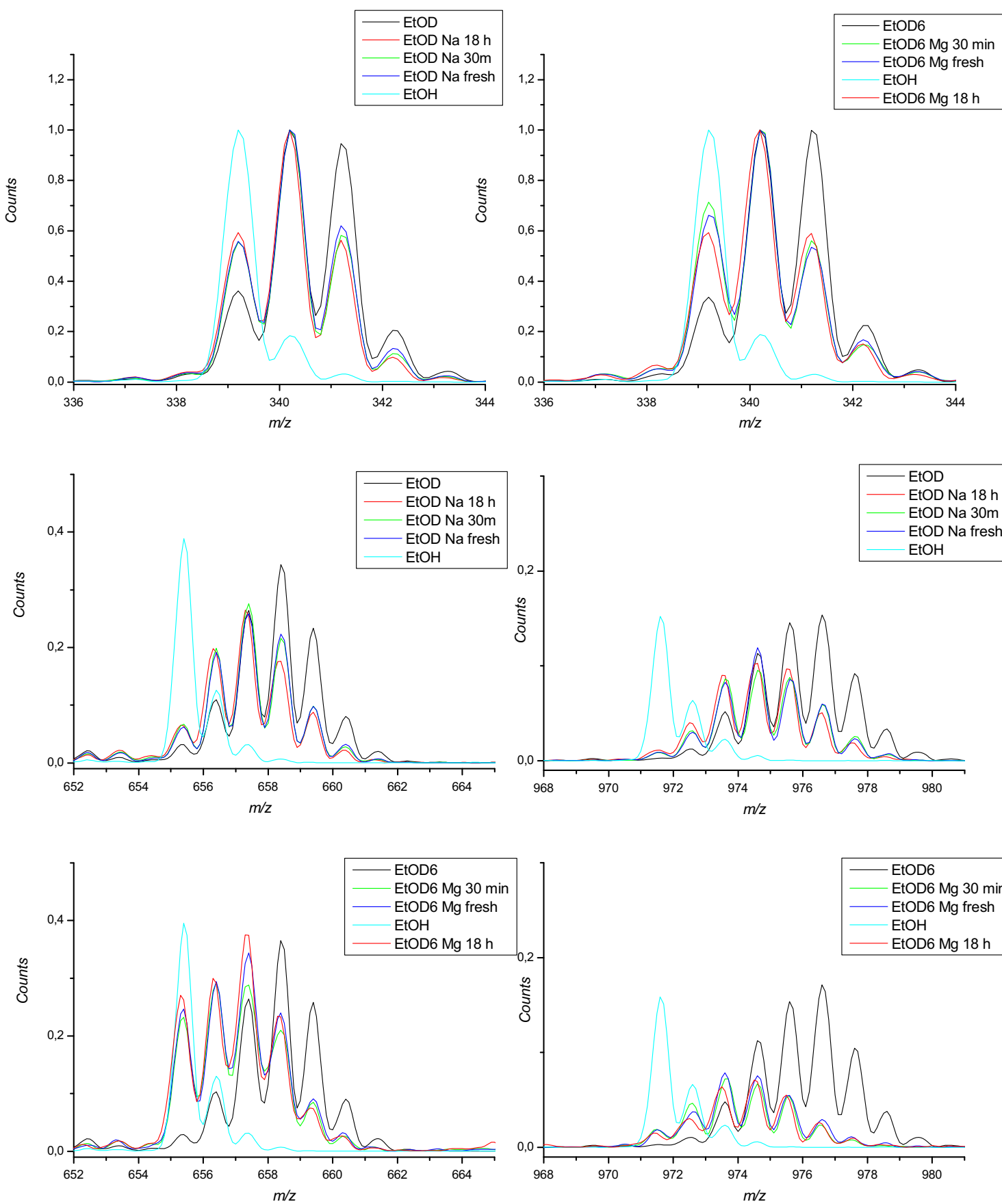

Figure 6. Overlaid mode of stretched out ES ${ }^{+}$spectra (monomer, dimer, and trimer) of compound 1 dissolved in ethanol, ethanold6, with and without $\mathrm{Mg}^{2+}$ or $\mathrm{Na}^{+}$in total concentration of $c=3 \times 10^{-5} \mathrm{~mol} \mathrm{dm}^{-3}$

third sodium ion disrupts the hydrogen bonding between the carboxylic units and thus prevents the formation of $\beta$-sheet type network (shown on Figure 5).

\section{Computational Analysis}

In order to rationalize the propensity of gelator molecules to assemble and to evaluate the effect of $\mathrm{Na}^{+}$cations on the aggregation, we performed a computational analysis using the M06-2X DFT functional in the gas phase. In doing so, we utilized a model analog of the gelator molecule 1 , since we demonstrated that it showed the best gelation properties, in which we replaced the isobutyl group by the methyl one to obtain 1a as shown in Figure 7.

It turns out that in isolated gas-phase systems, both trans-1a stereomers are around 9-10 $\mathrm{kcal} \mathrm{mol}^{-1}$ more stable than their cis- counterparts, with tG1 having the methyl groups on different sides of the plane, being the most stable system. This implies that cis-1a conformers are not favorable in the gas phase and their presence is very unlikely, being fully in line with experiments reported here. 
<smiles>[Y6]C(C(=O)O)N(NC(=O)C(=O)N[C@@H]([Y6])C(=O)O)C(=O)O</smiles>

trans-1a tG1<smiles>[Y6]C(NC(=O)C(=O)NC([14CH3])C(=O)O)C(=O)O</smiles>

trans-1a tG2<smiles>C[C@H](NC(=O)C(=O)N(C)[C@H](C)C(=O)O)C(=O)O</smiles>

cis-1a cG1<smiles>C[C@H](NC(=O)C(=O)NN(C(=O)O)[C@H](C)C(=O)O)C(=O)O</smiles>

cis-1a cG2

0.0

9.8

Figure 7. Different conformers and stereoisomers of $1 \mathrm{a}$ and their relative stabilities at the $\mathrm{M} 06-2 \mathrm{X} / 6-311++\mathrm{G}(\mathrm{d}, \mathrm{p}) / / \mathrm{M} 06-2 \mathrm{X} / 6-$ $31+\mathrm{G}(\mathrm{d})$ level of theory (in kcal mol ${ }^{-1}$ )

We investigated the aggregation of $\mathbf{1 a}$ molecules by sequentially adding individual monomers to the system to obtain the matching dimers, trimers, and tetramers. The calculated interaction free energies and schematic representation of the most stable structures are presented in Scheme 1, while the graphical representation of these aggregates is given in Supplementary Information Figure S7.

Dimerization of 1a is favorable in the gas phase with the interaction free energy of $-5.9 \mathrm{kcal} \mathrm{mol}^{-1}$. The dimer is stabilized through two types of hydrogen bonds: (a) those between the central amide fragments, and (b) those among the carboxyl units on both sides of 1a, which are persistent motifs also evident in higher aggregates (Scheme 1). In (tG1) $)_{2}$ dimer, hydrogen bonds in amide fragments are associated with $\mathrm{O}-\mathrm{N}$ distances of $2.96 \AA$, which appear to be out-dominated by the hydrogen bonds among carboxyl groups, where all four $\mathrm{O}-\mathrm{O}$ distances are shorter, being either 2.70 or $2.74 \AA$, suggesting the latter provides a prevailing stabilizing factor in the dimer.
This behavior could be rationalized by inspecting the intrinsic acidity and basicity of these fragments in 1a, since these are strongly related to their abilities to form and accept hydrogen bonds [36], respectively. In 1a, the carboxylic group is by $5.5 \mathrm{kcal} \mathrm{mol}^{-1}$ more $\mathrm{O}-\mathrm{H}$ acidic and by $4.1 \mathrm{kcal} \mathrm{mol}^{-1}$ more basic than the corresponding amide $\mathrm{N}-\mathrm{H}$ and carbonyl moieties, respectively, which both indicate stronger propensity of the former fragment to participate in the formation of hydrogen bonding. This trend is continued in the trimer $(\mathbf{t G 1})_{3}$, where the interacting $\mathrm{O}-\mathrm{N}$ distances assume 2.80 and $3.06 \AA$, whereas the corresponding $\mathrm{O}-\mathrm{O}$ distances are shorter and all are found at around $2.76 \AA$, the same being observable in the tetramer $(\mathbf{t G 1})_{4}$ as well. This led us to conclude that the aggregation of 1a molecules is primarily determined through the interaction of terminal carboxyl fragments, which allows favorable orientation for the hydrogen bonding among trans amide groups. Our attempts to model the intermolecular association of the carboxyl groups in tetramer (tG1 $)_{4}$ as in Figure 5 gave a much less

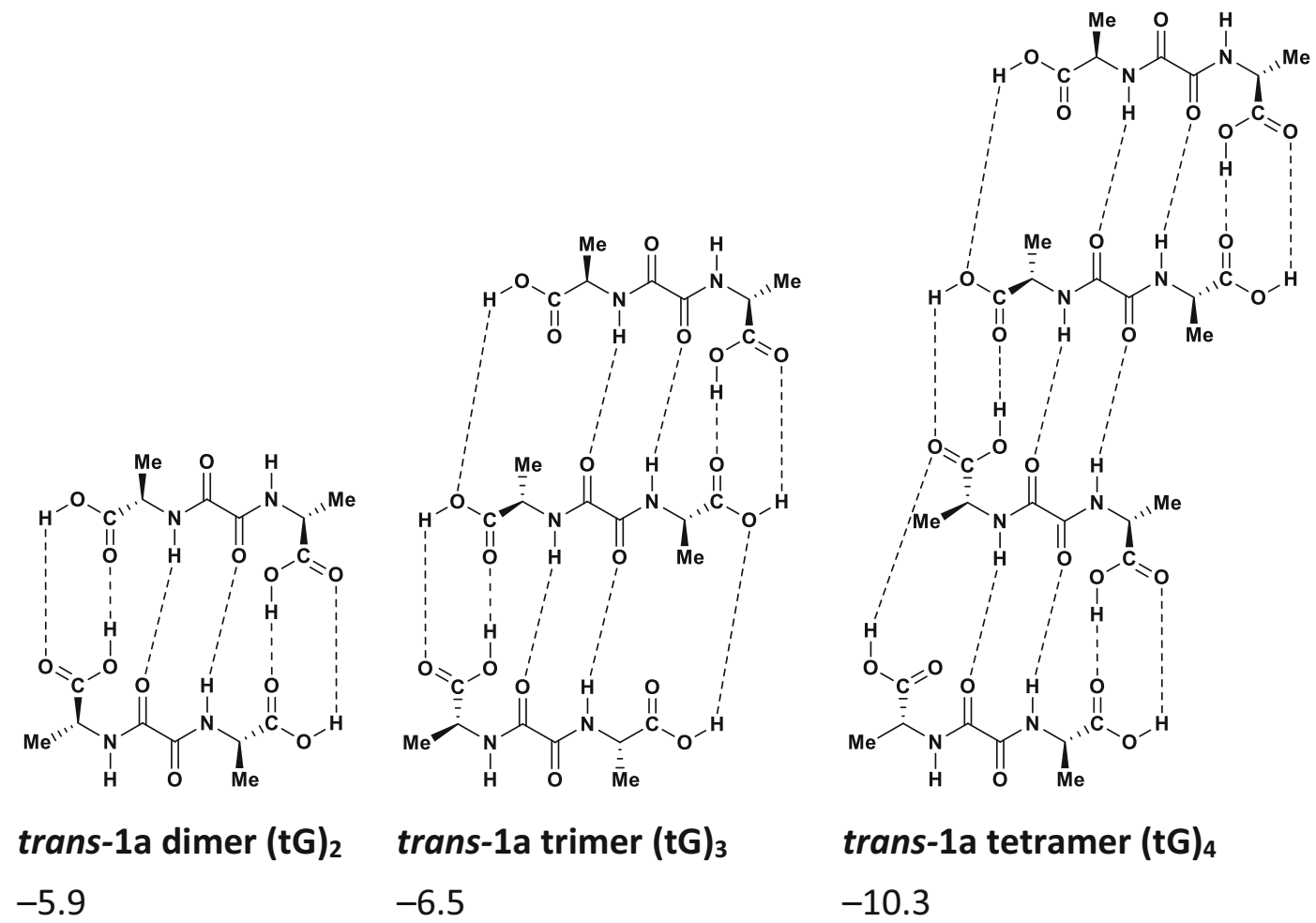

Scheme 1. Calculated gas-phase interaction free energies for the aggregation of 1a molecules at the M06-2X/6-311++G(d,p)// M06-2X/6-31+G(d) level of theory (all values in $\mathrm{kcal} \mathrm{mol}^{-1}$ ) 
stable system, leading us to conclude that such organization may be evident in much higher aggregates or in the solid state as explained earlier. The obtained interaction energies imply that the gelator aggregation is thermodynamically a favorable process and suggest that it will occur spontaneously in the gas phase with every additional monomer contributing moderately to the overall stabilization. In concluding this section, let us mention that our attempts to model the aggregation of $c i s-\mathbf{1 a}$ molecules resulted in either systems much less stable than the corresponding trans aggregates or the monomeric units spontaneously rotated to trans conformers during the geometry optimization. For example, the most stable cis-1a dimer is $23.6 \mathrm{kcal} \mathrm{mol}^{-1}$ less stable than its trans-1a analog.

Introduction of $\mathrm{Na}^{+}$cations into the system changes conformational and binding properties of $1 \mathrm{a}$ molecules. Interestingly, in $\mathbf{1 a}: \mathrm{Na}^{+}$complex there is an inversion of the stability in $\mathbf{1 a}$, with the cis-1a conformation becoming $0.2 \mathrm{kcal} \mathrm{mol}^{-1}$ more stable than the matching trans- $1 a$ due to the ability of the former to bind the $\mathrm{Na}^{+}$cation in a tridentate fashion (Scheme 2). In cis-1a: $\mathrm{Na}^{+}$complex, distances between carbonyl oxygens and the $\mathrm{Na}^{+}$cation are 2.30 and $2.36 \AA$, with one carboxyl group also binding $\mathrm{Na}^{+}$at $2.29 \AA$. A conformation with tetradentate $\mathrm{Na}^{+}$binding in cis-1a is also possible, but is $3.9 \mathrm{kcal} \mathrm{mol}^{-1}$ less stable. What is particularly interesting is that the interaction free energy in cis-1: $\mathrm{Na}^{+}$system is as high as
$-39.3 \mathrm{kcal} \mathrm{mol}^{-1}$, which is much higher than the energies calculated for the self-aggregation of $\mathbf{1 a}$ molecules. This convincingly suggests that the presence of the $\mathrm{Na}^{+}$cations easily disrupts the organization of 1a systems already at the level of 1:1 complexes. If we investigate the ability of $1 \mathbf{a}$ to bind two $\mathrm{Na}^{+}$cations, it turns out that trans-1a complex becomes $9.1 \mathrm{kcal}$ $\mathrm{mol}^{-1}$ more stable due to the fact that both $\mathrm{Na}^{+}$cations are bound on different sides of $1 \mathrm{a}$ with $\mathrm{Na}-\mathrm{Na}$ separation of $7.78 \AA$ (Scheme 2). It the cis counterpart, both $\mathrm{Na}^{+}$cations are placed much closer at $5.71 \AA$, which reduces the overall stability. Surprisingly, the calculated interaction free energy in 1:2 trans-1a: $\mathrm{Na}^{+}$complex is $-23.2 \mathrm{kcal} \mathrm{mol}^{-1}$, which is lower than in the 1:1 complex. This implies that the binding of two $\mathrm{Na}^{+}$ cations to one 1a molecule is less favorable than for one $\mathrm{Na}^{+}$ cation, demonstrating that the formation of $1: 2=\mathbf{1 a}: \mathrm{Na}^{+}$complex is very unlikely.

Binding of one $\mathrm{Na}^{+}$cation to two 1a molecules is even more favorable than in the corresponding 1:1 complexes. Complexation with trans-1a systems once again becomes more stable by $14.1 \mathrm{kcal} \mathrm{mol}^{-1}$ (Scheme 2), with the interaction free energy being further increased from the 1:1 complex to $-67.6 \mathrm{kcal}$ $\mathrm{mol}^{-1}$. This could be rationalized by the fact that $2: 1$ complex with trans-1a molecules, apart from the central tetracoordination of the $\mathrm{Na}^{+}$cation, allows for a significant hydrogen bonding among carboxyl groups between two gelators

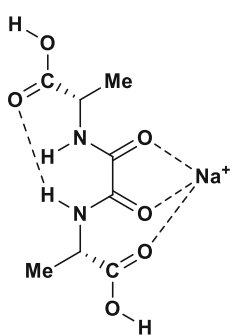

cis-1a $\cdots \mathrm{Na}^{+}$

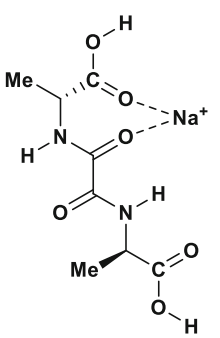

trans-1a $\cdots \mathrm{Na}^{+}$<smiles>C[C@H](NC(=O)[C@@H](C)NC(=O)[C@H](C)NC(=O)O)C(=O)O</smiles>

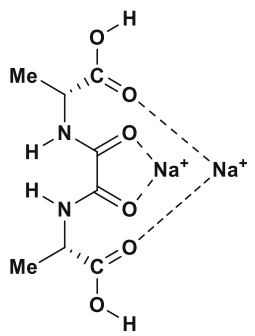

trans-1a $\cdots\left(\mathrm{Na}^{+}\right)_{2} \quad$ cis- $1 \mathrm{a} \cdots\left(\mathrm{Na}^{+}\right)_{2}$ $-23.2$ $-14.1$

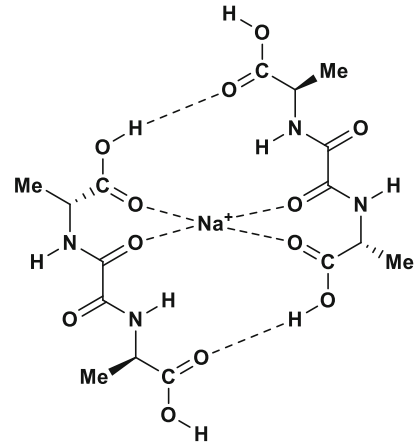

(trans-1a) $)_{2} \cdots \mathrm{Na}^{+}$

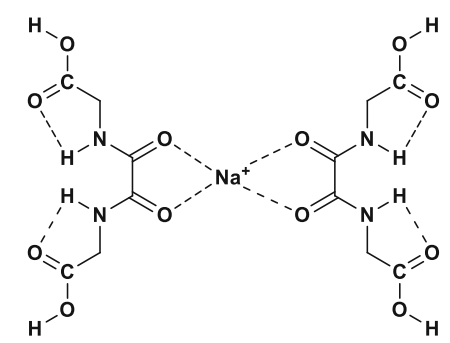

$(\text { cis-1a) })_{2} \cdots \mathrm{Na}^{+}$

Scheme 2. Calculated gas-phase interaction free energies for the complexation between 1 a molecules and $\mathrm{Na}^{+}$cations at the

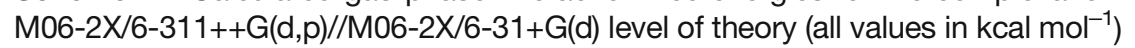


(Scheme 2), which is absent in both cis-1a. In other words, in $2: 1=$ trans $-1 \mathbf{a}: \mathrm{Na}^{+}$complex, the corresponding $\mathrm{O}-\mathrm{O}$ distances in the hydrogen bonded carboxyl groups are both $2.75 \AA$, being almost perfectly linear at $174.9^{\circ}$. This even allows shorter $\mathrm{Na}-$ O distances in the central part, being 2.22 and $2.26 \AA$, which suggest stronger binding than in cis-1a where these assume $2.29 \AA$.

A single $\mathrm{Na}^{+}$cation can bind three 1a molecules and this indeed occurs in the gas phase, again much more likely with trans-1a. In this case (Supplementary Information Fig. S7), each $1 \mathrm{a}$ coordinates $\mathrm{Na}^{+}$in a bidentate way fully analogous to that found in 1:1 complex, in other words with one carbonyl group and the neighboring carboxyl group. In doing so, all three 1a molecules form an octahedron around the $\mathrm{Na}^{+}$cation with the corresponding $\mathrm{Na}-\mathrm{O}$ distances of $2.23 \AA$ towards the carbonyl oxygens and $2.46 \AA$ towards cyrboxyl oxygens. Although this proceeds without any significant intermolecular interaction among the rest of $\mathbf{1 a}$ molecules, the calculated gasphase interaction free energy is $-71.9 \mathrm{kcal} \mathrm{mol}^{-1}$, being the highest in all studied 1a: $\mathrm{Na}^{+}$complexes. This convincingly implies that the formation of the $3: 1=\mathbf{1}: \mathrm{Na}^{+}$complex is very likely and thermodynamically favorable, and rationalizes the experimentally observed fact that the dominant signal in the MS spectra corresponds exactly to this system. It also demonstrates that the presence of the $\mathrm{Na}^{+}$cations in the system will undoubtedly disrupt any self-organization or assembly of the individual 1a molecules, since the electrostatic interactions with $\mathrm{Na}^{+}$cations significantly outperform interactions among 1a's. This is fully in line with experimental findings presented here.

\section{Conclusion}

The idea was to explore the difference in self-organization in the gas phase as the indicator of molecular recognition interactions between the oxalamide building blocks and that the physical linking could be observed because of the noncovalent supramolecular interactions. We observed selfassembled aggregates formed because of the strong intermolecular hydrogen bonding even though the transition from condensed phase into the high vacuum of the mass spectrometer could change the properties of the non-covalent bonds such as strength, directionality, and geometry. Taking all of this into account, we believe that the observed results in the gas phase could be related to the gelation properties of presently studied four compounds. Namely, compound $\mathbf{1}$ formed large stable aggregates in all studied solutions. Compounds $\mathbf{2}$ and $\mathbf{3}$ are not as good gelators as $\mathbf{1}$, and did not preserve self-aggregation in the gas phase. The addition of metal ions disrupts the gelator network supported with the hydrogen bonding, which is fully corroborated by DFT calculations. These computations revealed that the presence of the $\mathrm{Na}^{+}$cations in the system disrupts any self-organization of the individual $\mathbf{1}$ molecules since the electrostatic interactions with $\mathrm{Na}^{+}$cations significantly outperform interactions among $\mathbf{1}$ 's, being fully in line with experimental findings presented here.

\section{Acknowledgements}

The authors gratefully acknowledge Dr. J. Makarević, (Laboratory for Supramolecular Chemistry, Division of Organic Chemistry and Biochemistry, Ruđer Bošković Institute, Zagreb, Croatia) for aid in the synthesis of gelators and the preparation of gels samples. This work was supported by the Ministry of Science, Education, and Sports of the Republic of Croatia under grant number 098-0982914-2935. R.V. gratefully acknowledges the financial support from the Croatian Science Foundation (HRZZ) under grant number IP-2014-093386 and L.F. under grant number IP-11-2013-7387.

\section{References}

1. de Loos, M., van Esch, J., Kellog, R.M., Feringa, B.L.: Chiral recognition in bis-urea-based aggregates and organogels through cooperative interactions. Angew. Chem., Int. Ed. 40, 613-616 (2001)

2. Terrech, P., Weiss, R.G.: Low molecular mass gelators of organic liquids and the properties of their gels. Chem. Rev. 97, 3133-3160 (1997)

3. Weiss, R.G., Terrech, P.: Molecular gels, materials with self-assembled fibrillar networks. Springer, P.O. Box 17, 3300 AA Dordrecht, The Netherlands (2006)

4. Weiss, R.G.: The past, present, and future of molecular gels. What is the status of the field, and where is it going? J. Am. Chem. Soc. 136, 75197530 (2014)

5. Jokić, M., Makarević, J., Žinić, M.: A novel type of small organic gelators: bis(amino acid) oxalyl amides. J. Chem. Soc. Chem. Commun. 17, 1723-1724 (1995)

6. Makarević, J., Jokić, M., Perić, B., Tomišić, V., Kojić-Prodić, B., Žinić, M.: Bis(amino acid) oxalyl amides as ambidextrous gelators of water and organic solvents: supramolecular gels with temperature dependent assembly/dissolution equilibrium. Chem. Eur. J. 15, 3328-3341 (2001)

7. Makarević, J., Jokić, M., Raza, Z., Štefanić, Z., Kojić-Prodić, B., Žinić, M.: Chiral bis(amino alcohol) oxalyl amide gelators-gelation properties and supramolecular organization. Racemate versus pure enantiomer gelation. Chem. Eur. J. 9, 5567-5580 (2003)

8. Makarević, J., Jokić, M., Frkanec, L., Čaplar, V., Šijaković Vujičić, N., Žinić, M.: Oxalyl retro-peptide gelators. Synthesis, gelation properties, and stereochemical effects. Beilstein J. Org. Chem. 6, 945-959 (2010)

9. Miljanić, S., Snežana, F.L., Biljan, T., Meić, Z., Žinić, M.: Surfaceenhanced Raman scattering on molecular self-assembly in nanoparticlehydrogel composite. Langmuir. 22, 9079-9081 (2006)

10. Makarević, J., Jokić, M., Frkanec, L., Katalenić, D., Žinić, M.: Gels with exceptional thermal stability formed by bis(amino acid) oxalamide gelators and solvents of low polarity. Chem. Commun. 19, 2238-2239 (2002)

11. Čaplar, V., Frkanec, L., Šijaković Vujičić, N., Žinić, M.: Positionally isomeric organic gelators: structure-gelation study, racemic versus enantiomeric gelators, and solvation effects. Chem. Eur. J. 16, 3066-3082 (2010)

12. Yu, G., Yan, X., Han, C., Huang, F.: Characterization of supramolecular gels. Chem. Soc. Rev. 42, 6697-7622 (2013)

13. Hui, J.K.-H., Yu, Z., MacLachlan, M.J.: Supramolecular Assembly of Zinc Salphen Complexes: Access to Metal-Containing Gels and Nanofibers. Angew. Chem. Int. Ed. 46, 7980-7983 (2007)

14. Zhang, J., Xu, X.-D., Chen, L.-J., Luo, Q., Wu, N.-W., Wang, D.-X., Zhao, X.-L., Yang, H.-B.: Platinum acetylide complexes containing iptycene as cores: a new family of unexpected efficient organometallic gelators. Organometallics. 30, 4032-4038 (2011)

15. Chen, L.-J., Zhang, J., He, J., Xu, X.-D., Wu, N.-W., Wang, D.-X., Abliz, Z., Yang, H.-B.: Organometallics. 30, 5590-5594 (2011)

16. Fenn, J.B.: Electrospray wings for molecular elephants (Nobel Lecture). Angew. Chem. Int. Ed. 42, 3871-3794 (2003)

17. Fenn, J.B., Mann, M., Meng, C.K., Wong, S.F., Whitehouse, C.M.: Electrospray ionization - principles and practice. Mass Spectrom. Rev. 9, 37-70 (1990) 
18. Baytekin, B., Baytekin, H.T., Schalley, C.A.: Mass spectrometric studies of non-covalent compounds: why supramolecular chemistry in the gas phase? Org. Biomol. Chem. 4, 2825-2841 (2006)

19. Schalley, C.A.: Molecular recognition and supramolecular chemistry in the gas phase. Mass Spectrom. Rev. 20, 253-309 (2001)

20. Schalley, C.A.: Supramolecular chemistry goes gas phase: the mass spectrometric examination of noncovalent interactions in host-guest chemistry and molecular recognition. Int. J. Mass Spectrom. 194, 11-39 (2000)

21. Schalley, C.A.: Springer, mass spectrometry and gas-phasechemistry of non-covalent complexes. Wiley, Hoboken, NJ (2009)

22. Makarević, J., Jokić, M., Perić, B., Tomišić, V., Kojić-Prodić, B., Žinić, M.: Bis(amino acid) oxalyl amides as ambidextrous gelators of water and organic solvents: supramolecular gels with temperature dependent assembly/dissolution equilibrium. Chem. Eur. J. 7, 3328-3341 (2001)

23. Maršavelski, A., Smrečki, V., Vianello, R., Žinić, M., MogušMilanković, A., Šantić, A.: Supramolecular ionic liquid gels with high ionic conductivity. Chem. Eur. J. 21, 12121-12128 (2015)

24. Škalamera, Đ., Sanders, E., Vianello, R., Maršavelski, A., Pevec, A., Turel, I., Kirin, S.I.: Synthesis and characterization of ML and ML2 metal complexes with amino acid substituted bis(2-picolyl)amine ligands. Dalton Trans. 45, 2845-2858 (2016)

25. Gregorić, T., Sedić, M., Grbčić, P., Tomljenović, A., Paravić, S., Pavelić, K., Cetina, M., Vianello, R., Raić-Malić, S.: Novel pyrimidine-2,4-dione1,2,3-triazole and furo[2,3-d]pyrimidine-2-one-1,2,3-triazole hybrids as potential anti-cancer agents: Synthesis, computational and X-ray analysis, and biological evaluation. Eur. J. Med. Chem. 125, 1247-1267 (2017)

26. Šakić, D., Šonjić, P., Tandarić, T., Vrček, V.: Chlorination of Nmethylacetamide and amide-containing pharmaceuticals. Quantumchemical study of the reaction mechanism, J. Phys. Chem. A. 118, 2367-2376 (2014)

27. Maršavelski, A., Vianello, R.: What a difference a methyl group makes: the selectivity of monoamine oxidase B towards histamine and Nmethylhistamine. Chem. Eur. J. 23, 2915-2925 (2017)

28. Frisch, M.J., Trucks, G.W., Schlegel, H.B., Scuseria, G.E., Robb, M.A., Cheeseman, J.R., Scalmani, G., Barone, V., Mennucci, B., Petersson, G.A., Nakatsuji, H., Caricato, M., Li, X., Hratchian, H.P., Izmaylov, A.F., Bloino, J., Zheng, G., Sonnenberg, J.L., Hada, M., Ehara, M., Toyota, K.,
Fukuda, R., Hasegawa, J., Ishida, M., Nakajima, T., Honda, Y., Kitao, O., Nakai, H., Vreven, T., Montgomery Jr., J.A., Peralta, J.E., Ogliaro, F., Bearpark, M., Heyd, J.J., Brothers, E., Kudin, K.N., Staroverov, V.N., Kobayashi, R., Normand, J., Raghavachari, K., Rendell, A., Burant, J.C., Iyengar, S.S., Tomasi, J., Cossi, M., Rega, N., Millam, J.M., Klene, M., Knox, J.E., Cross, J.B., Bakken, V., Adamo, C., Jaramillo, J., Gomperts, R., Stratmann, R.E., Yazyev, O., Austin, A.J., Cammi, R., Pomelli, C., Ochterski, J.W., Martin, R.L., Morokuma, K., Zakrzewski, V.G., Voth, G.A., Salvador, P., Dannenberg, J.J., Dapprich, S., Daniels, A.D., Farkas, Ö., Foresman, J.B., Ortiz, J.V., Cioslowski, J., Fox, D.J.: Gaussian 09, Revision A.02. Gaussian, Inc., Wallingford, CT (2009)

29. Karle, I.L., Ranganathan, D., Shah, K., Vaish, N.K.: Conformation of the oxalamide group in retro-bis-peptides. Int. J. Peptide Prot. Res. 43, 160 165 (1994)

30. Karle, I.L., Ranganathan, D.: The delineation of hydrogen-bonding patterns in supramolecular self-assembly of several core oxalo retro-peptides and crystal structure of MeO-Ser-Leu-COCO-Leu-Ser-OMe. Int. J. Peptide Prot. Res. 46, 18 (1995)

31. Karle, I.L., Ranganathan, D.: Polymethylene spacer linked bis(A1a) peptides form modified $\beta$ :-sheet structures: crystal structure and selfassembly pattern of adipoyl and sub-eroyl analogues. Int.J.Peptide Prot. Res. 46, 24-29 (1995)

32. Frkanec, L., Žinić, M.: Chiral bis(amino acid)- and bis(amino alcohol)oxalamide gelators. Gelation properties, self-assembly motifs, and chirality effects. Chem. Commun. 46, 522-537 (2010)

33. Gareth, O., Steed, J.W.: Anion-tuning of supramolecular gel properties. Nat. Chem. 1, 437-442 (2009)

34. Meazza, L.J., Foster, A., Fucke, K., Metrangolo, P., Resnati, G., Steed, J.W.: Halogen-bonding-triggered supramolecular, gel formation. Nat. Chem. 5, 42-47 (2013)

35. James, S.J., Perrin, A., Jones, C.D., Yufit, D.S., Steed, J.W.: Highly interlocked anion-bridged supramolecular networks from interrupted imidazole-urea gels. Chem. Commun. 50, 12851-12854 (2014)

36. Gilli, P., Pretto, L., Bertolasi, V., Gilli, G.: Predicting hydrogen-bond strengths from acid-base molecular properties. The $\mathrm{pK}(\mathrm{a})$ slide rule: toward the solution of a long-lasting problem. Acc. Chem. Res. 42, 3344 (2009) 